\title{
The Influence of Media on the State Supervision System
}

\section{Muhammad Abrar Azizi}

Institut Agama Islam (IAI) Al-Aziziyah Samalanga, Bireuen Aceh, Indonesia

Email: azizi@iaialaziziyah.ac.id

\begin{abstract}
:
Dayah is the oldest dakwah development institution in the archipelago, which emphasizes the formation of community morals to be civilized and polite. At first the dayah was not only a place for community religious learning, but also as a school institution to study general education, but when colonialism took place in this country, education was divided into two categories, namely religion and general. From then on, the effect of the decline in dayah education occurred, so that the interest of the community to study in the dayah was reduced and the function of the dayah began to change from its existence. Dayah institutions exist in society, and are community-owned educational institutions, which are built and developed by the community themselves independently. Dayah institutions are still consistent with religious education, so that this becomes a distinctive feature for dayah which is different from other educational institutions. Dayah has a special education system and pattern that is arranged in the form of a curriculum that is taught to its students. This learning pattern aims to be able to give birth to future generations who have strong faith and have broad insight.
\end{abstract}

Keywords: influence; media; supervision system

\section{Introduction}

Mass media is a form of technological advancement in the field of information and communication. The influence of the mass media varies on each individual or group. This is due to differences in thought patterns, differences in traits that have an impact on attitude making, day-to-day social relations, and cultural differences. Supervision is very important in every government administration, both regional and central government, because with the supervision of every activity or program it will avoid irregularities such as corruption and with supervision of activities or programs from the government it will be right on target according to the previously planned objectives.

Without realizing it, the mass media has had its own impact on a country's surveillance system. The most pronounced impact is how decisions taken by the government are often the influence of what is reported by the mass media, even though the actual reality is far from what is reported. This has clearly reduced the credibility of a government institution which shows how the power of the mass media today greatly influences policies in running the country. 


\section{Review of Literatures}

\subsection{Understanding Mass Mediaa}

Mass media stands for mass media of communication or media of mass communication. Mass media is "communication using means or equipment that can reach the masses as much as possible and an area as wide as possible". "Mass communication cannot be separated from the masses, because in mass communication, the delivery of messages is through the media." McQuail stated that mass media is a powerful source of control, management, and innovation tools in society that can be utilized as a substitute for other strengths or resources.

Mass media is a tool used in conveying the message from the source to the audience by using mechanical means of communication, such as newspapers, radio, television and etc. In this case, here the mass media is print media or newspapers. According to Bitter (in Muhtadi, 1999: 73), mass media is a means of transmitting information, such as newspapers, magazines, books, films, radio and television, or a combination of shapes of media forms. Meanwhile, according to Cangara (2002: 134), mass media is a tool used in the delivery of a message from the source to the audience (receiver) using a mechanical of communication such as newspapers, radio, film and television. (Saragih, 2018)

The media has assumed more of a negative role in this negotiation process. The role of the media is important in public issues like this. The media is supposed to be informing the public about issues and interests affecting the country. During reporting the Medias are also expected to be impartial and truthful to the information they are providing to the people. Impartial and good reporting can bring transparency and accountability of the parties involved in the process. (Woldemaryam, 2020). Not only that, the media can also be the dominant source consumed by the community to obtain images and images of social reality both individually and collectively, where the media present normative values and judgments mixed with news and entertainment.

\section{a. Characteristics of Mass Media} follows:

Furthermore, mass media has several characteristics as expressed by Cangara as

1. Institutional in nature: the party who manages the media consists of many people, starting from the collection, management, to the presentation of information.

2. One-way: the communication made does not allow dialogue between the sender and the receiver. If for example there is a reaction or feedback it usually takes time and is delayed.

3. Broad and in unison: can overcome the obstacles of time and distance because it has speed. Moving broadly and simultaneously, where the information conveyed is received by many people at the same time.

4. Using technical or mechanical equipment: such as radio, television, newspapers, and the like.

5. Open nature: messages can be received by anyone and anywhere regardless of age, gender, religion and ethnicity. Some forms of mass media include mechanical means of communication such as newspapers, films, radio and television.

Mass media consists of print media (newspapers, magazines, etc.) and non-print or electronic media (radio, TV, internet, films). Electronic media (film, radio, and television) itself has a very different history from print media. As a product of the industrial and technological revolution, electronic media emerged when democracy in the US was fully developed and urbanization had been going on for a long time, complete with the various problems it 
brought. Because of this, since the beginning, electronic media has been democratic in nature, and from the very beginning its audience has been the wider community as a whole, not just certain groups.

Previously, unlike print media, electronic media demanded its audiences to pay full attention because what they broadcast would not be repeated. We can read about the plateau now, then pass it on ten years later. We can not enjoy radio and television broadcasts like that, but audio and video technology then change it, because we can record certain things for us to enjoy at any time outside when the program is broadcast. Technology is the nature of electronics, and the need for great support requires that film, radio and television have a large or mass audience. Even radio programs or short films are expensive and require a wide range of skills from screenwriters, producers, directors, performers, engineers and technicians to handle a variety of equipment. To cover all these costs a large audience is required.

\section{b. Mass Media Functions}

The functions of the mass media are:

1. Information

Provides information about events and conditions in society and the world Shows, power relations, Facilitates innovation, adaptation and progress.

2. Correlation

Explaining, interpreting, commenting on the meaning of events and information, supporting established authority and norms, conducting socialization, coordinating several activities, forming agreements, determining priority sequences and assigning relational status.

3. Continuity

Expressing a dominant culture and acknowledging the existence of a special culture (subculture) as well as the development of new cultures, enhancing and preserving values.

4. Entertainment

Provides entertainment, diversion and means of relaxation, relieves social tensions.

5. Mobilization

Dismiss the goals of society in the fields of politics, development, economy, work and religion.

\section{c. Definition of Supervision}

The term supervision in Indonesian, the origin of the word is "watch out", while in English it is called controlling which is translated as supervision and control, so that the term controlling has a broader meaning than supervision. However, among experts or scholars the notion of "controlling" has been equated with supervision. So supervision is including control. Control comes from the word "control", so that control means directing, correcting, activities, which are misdirected and straighten them towards the right direction. However, there are also those who disagree with the equality of the term controlling with supervision.

\section{d. Purpose and Objectives of Supervision}

In the framework of implementing the work and to achieve the planned goals of the government, there is need for supervision, because with this supervision, the objectives to be achieved can be seen based on plans that have been predetermined by the government. Thus supervision is very important in carrying out government jobs and tasks, so that supervision is held with the intention of:

1. Knowing the course of work, whether smooth or not

2. Correct mistakes made by employees and take precautions so that the same mistakes do not happen again or new ones arise. 
3. Knowing the implementation of work in accordance with the program as determined in the planning or not

With regard to the objectives of supervision, Situmorang and Juhir suggest the creation of a clean and authoritative apparatus which is supported by an efficient and effective government management system and is supported by constructive and controlled community participation in the form of objective, healthy social control and take responsibility. Based on the opinions of the experts above, it can be seen that in essence the purpose of supervision is to compare the implementation and plans and instructions that have been made, to determine whether there are difficulties, weaknesses or failures as well as work efficiency and effectiveness and to find a way out if there are difficulties, weaknesses. and failure or in other words called corrective action.

\section{e. Kinds of Supervision}

In terms of supervision, various types of supervision can be classified based on various things, namely:

1. Direct supervision and indirect supervision

Direct supervision is supervision that is carried out personally by the leader or supervisor by observing, researching, checking, self-checking "on the spot" at the work place and receiving reports directly from the executor. Meanwhile, indirect supervision is held by studying reports received from the executor, both oral and written, studying public opinions and without supervision.

\section{Preventive and Repressive Monitoring}

Although the principle of supervision is preventive, when it is related to the time of execution of the work, a distinction can be made between Preventive Supervision and Repressive Supervision. Preventive Supervision relating to the ratification of certain Regional Regulations or Regional Head Decrees. Because not all Regional Regulations and Regional Head Decrees require endorsement. As long as the legalization has not been obtained, the Regional Regulation or the Decree of the Head of the Region concerned is not yet effective and this supervision is carried out through pre-audit before work begins. For example, by supervising preparations, work plans, budget plans, plans for the use of manpower and other resources. Meanwhile, Repressive Monitoring can take the form of postponement or cancellation. A Regional Regulation or Decree of a Regional Head that is already in effect and has binding power can be suspended or canceled because it is contrary to public interest or higher-level laws and regulations and this supervision is carried out through a post audit by examining the implementation on the spot, requesting an implementation report and so.

\section{Internal Control and External Control}

Internal Control, is the supervision carried out by the apparatus within the organization itself. Basically, supervision must be carried out by the top leaders themselves. However in practice this is not always possible. Therefore, every leader in the organization is basically obliged to assist the top leaders to carry out functional supervision in accordance with their respective areas of duty. Meanwhile, External Control is supervision carried out by officials from outside the organization itself. Such as supervision in the financial sector by the Supreme Audit Agency as long as it covers all State Apparatus and the Directorate General of State Financial Supervision of Ministries and other government agencies.

These kinds of controls are based on the classification of controls. Besides that, there are also several types of supervision seen from the field of supervision, namely:

- Budgetary control

- Control costs (cost control) 
- Inventory control

- Production control (production control)

- Supervision of the amount of work (quality control)

\section{Results and Discussion}

\section{Media Influence on State Surveillance System}

The mass media is a propaganda tool that is very effective and is often used by the government and political elites. For example, in Indonesia, since the Soeharto regime, the mass media have become a means of controlling the public. The government and military officials continued to harass and intimidate journalists until Suharto's resignation. The events of May '98 have illustrated the failure of the Soeharto regime in understanding local and international media, and the political effect of media and information technology, as a 'force' to organize communication to become more and more practical.

In fact, so far the mass media have not been used properly, namely as a means of monitoring government. Even though the authoritarian Suharto regime had changed to SBY's democratic regime, mass media was still only owned and utilized by certain groups such as capital owners, people who had influence / pressure groups, political elites, and so on. Charismatic leaders are used by the media to project 'their' image. Where charisma is combined with the media to create a 'celebrity', it becomes an increasingly important element in the political process.

The control exercised by the central government over the media is a characteristic of recent press development in Indonesia. Some asked the media to directly control and set the agenda for the government and politicians because society is always influenced by the content of the media. Even so, if we return to the uses and gratification theory as well as several other theories about the mass media, then the public will clearly have a filter to absorb the information conveyed by the media even though they are continuously being injected by the practice of media propaganda. As a reflection of democratization in Indonesia, the birth of new media can become the center of the democratic process through (alternative) media. In any form, the media are conveyors of information that are sometimes news-worthy and are always sought after by the public, especially in a crisis. News programs may receive high ratings during a crisis, for example: natural disasters. In addition, the main strength of the mass media in a crisis is the function of correlation and supervision which can build solidarity and reduce tensions. Moreover, in a crisis situation, the mass media still has 4 permanent functions, namely: monitoring, correlation, socialization and entertainment.

As viewers spend more time with the media, the logic of advertising, entertainment and pop culture becomes a normal form of communication. But besides that, we must first be aware of how powerful mass media propaganda is, and position ourselves to believe in any part of the media. In the attack on the WTC building in the United States, several examples of propaganda were stored. Such as the broadcast of the attack on the second building by the New York newspapers. After the incident, America declared that Terrorists were the enemies of the world. whereas, something can be said to be an enemy of the world if it has attacked more than one country. In this respect, the war on terrorism is a controversy in much the same way that the cold war is a war of ideology. Thus, a more coherent propaganda or perception management is needed. A battle is always faced with the realities of intelligence, law, finance, homeland defense, diplomacy - and propaganda. Now, the global information environment has become an information hole and is very fast in disseminating information as a campaign strategy (propaganda). 
The understanding of local and international media, and the political effect of media and information technology, as' the power to organize communication is becoming more and more practical. Changes in information technology in a capitalistic context have changed the processes, products and social effects of mass communication. This change in terms of information technology has a very big effect on how the understanding of "viewers" is to what is presented by the mass media, including motivation and abilities that are attributes as members of the audience who own, operate, and regulate mass communication.

Leadership programs define their target audience as a heterogeneous audience, especially for women aged 18 - 49 years. they are the ones who closely follow the changes in information technology. One very important aspect of defining a situation is social identity. mass media is the key to the identity process in the postmodern world. The effect of mass media on social identity is also evident in the development of electronic communication on a large scale, or the term viewers as "E-audiences".

\section{Conclusion}

Mass media has a very big influence on various dimensions, both in the fields of economy, politics, law, social, agriculture, education, health and so on. Mass media is the main mouthpiece of change in society or the state towards improving people's lives in various dimensions. But in this case too, the mass media has two principal functional roles, namely positive and negative. It remains how we see and take the benefits. A great nation is also because of the mass media, so it can also be destroyed because of the mass media. That is why the surveillance system of a country is never separated from the mass media. Many influences have been given to the continuity of a government, including the policies taken by a government which cannot be separated from a point of view formed by the mass media.

\section{References}

BN. Marbun. (1993). DPRD Growth, Problems and Its Future, Jakarta: Erlangga.

Cangara. (2003). Introduction to Communication Studies, PT Raja Grafindo Persada, Jakarta.

Mc Quail, Denis. (1987). An Introduction to Mass communication Theory. trans. Agus Dharma and Aminuddin Ram. Jakarta: Erlangga.

Philipus. (1999). Introduction to Indonesian Administrative Law, Yogjakarta: Gadjah Mada University Press.

Rivers, et al. (2008). Mass Media \& Modern Society. Jakarta: Kencana.

Saragih, M. (2018). Some Characteristics of Islamic Journalism Based on Al Quran. Budapest International Research and Critics Institute-Journal (BIRCI-Journal). P. 01-10

Victor, M. Situmorang, and Jusuf Juhir. (1994). Legal Aspects of Inherent Supervision, Yogyakarta, Rineka Cipta.

Woldemaryam, E. (2020). Making the Nile River a Point of Cooperation between Ethiopia and Egypt: Building Confidence through Water Diplomacy. Budapest International Research and Critics Institute-Journal (BIRCI-Journal). P. 2494-2500. 